\title{
Mesoscopic Numerical Computation of Compressive Strength and Damage Mechanism of Rubber Concrete
}

\author{
Z. H. Xie, ${ }^{1}$ Y. C. Guo, ${ }^{2}$ Q. Z. Yuan, ${ }^{2}$ and P. Y. Huang ${ }^{1}$ \\ ${ }^{1}$ School of Civil Engineering and Transportation, South China University of Technology, Guangzhou 510641, China \\ ${ }^{2}$ Faculty of Civil and Transportation Engineering, Guangdong University of Technology, Guangzhou 510006, China \\ Correspondence should be addressed to Y. C. Guo; guoyc@gdut.edu.cn
}

Received 19 March 2015; Accepted 22 June 2015

Academic Editor: João M. P. Q. Delgado

Copyright (c) 2015 Z. H. Xie et al. This is an open access article distributed under the Creative Commons Attribution License, which permits unrestricted use, distribution, and reproduction in any medium, provided the original work is properly cited.

\begin{abstract}
Evaluations of both macroscopic and mesoscopic strengths of materials have been the topic of a great deal of recent research. This paper presents the results of a study, based on the Walraven equation of the production of a mesoscopic random aggregate structure containing various rubber contents and aggregate sizes. On a mesoscopic scale, the damage mechanism in the rubber concrete and the effects of the rubber content and aggregate-mortar interface on the rubber concrete's compressive resistance property were studied. The results indicate that the random aggregate structural model very closely approximates the experimental results in terms of the fracture distribution and damage characteristics under uniaxial compression. The aggregate-mortar interface mechanical properties have a substantial impact on the test sample's strength and fracture distribution. As the rubber content increases, the compressive strength and elastic modulus of the test sample decrease proportionally. This paper presents graphics of the entire process from fracture propagation to structural failure of the test piece by means of the mesoscopic finite-element method, which provides a theoretical reference for studying the damage mechanism in rubber concrete and performing parametric calculations.
\end{abstract}

\section{Introduction}

Rubber concrete is a concrete-based composite material that uniformly blends rubber powder or rubber particles into a cemented material. Compared with conventional concrete, rubber concrete is lightweight, durable, and better at damping shocks, resists impacts and spalling well, and displays good heat insulation qualities due to the rubber particles [1-3]. Studies [4-7] have shown that the compressive resistance of rubber concrete decreases significantly as the rubber content increases, whereas the rubber particle size is not significant. However, recent studies of rubber concrete have been primarily based on experiments [2-8], which demand a large amount of manpower and resources, and the results are somewhat inconclusive due to changes in experimental and environmental conditions and the complexity of the material itself. Moreover, macroscopic experiments have not revealed the mechanism of damage to rubber concrete.

Finite-element mesoscopic analysis of concrete-type materials can clearly reveal the entire process of fracture initiation and propagation to damage in the various internal constituents under stress. Scholars have performed many meaningful numerical mesoscopic-scale studies of analogous concrete materials. For example, Kwan et al. [9] used zerothickness interface elements to simulate the uniaxial cracking process in a random aggregate concrete model. Ma et al. [10] performed a numerical uniaxial compression simulation and three-point loaded-beam bending experiment on a random concrete aggregate model based on plastic damage. Du et al. [11] used an extended finite-element method to numerically simulate the uniaxial tensile strength and Winkler L plate mesoscopic fracture process. However, mesoscopic numerical studies of rubber concrete are relatively scarce. Liu et al. [12] treated rubber concrete as a dual-phase composite material composed of concrete and rubber and calculated its uniaxial compressive strength on a mesoscopic scale. Their results indicate that errors in the bearing capacity values range from $2.6 \%$ to $21.1 \%$ compared to the experimental values, and thus the simulation results may be considered to be representative and valid. Rubber absorbs a relatively small force during the damage process and behaves elastically. Wang et al. [13] viewed rubber asphalt concrete as a 
TABLE 1: Rubber concrete mix ratio.

\begin{tabular}{lccccc}
\hline \multirow{2}{*}{ Test sample designation } & & \multicolumn{3}{c}{ Unit volume material content $\left(\mathrm{kg} / \mathrm{m}^{3}\right)$} \\
& Added water & Concrete & Sand & Natural aggregate & Rubber content \\
\hline NCR0 & 195 & 375 & 658.8 & 1171 & 1171 \\
NCR10 & 195 & 375 & 593 & 1171 & 27.7 \\
NCR20 & 195 & 375 & 527 & 55.4 \\
\hline
\end{tabular}

dual-phase composite material composed of coarse aggregate and rubber mixed with asphalt mortar. They simulated the cracking process using an extended finite-element method with the assistance of X-ray CT. The results indicate that the numerical values are very close to the experimental ones. These numerical analyses of rubber concrete focused on its strength, and no studies of its damage mechanism have been reported.

In this paper, rubber concrete is viewed as a fourphase composite material composed of rubber, coarse aggregate, mortar, and aggregate-mortar interfaces. The twodimensional random aggregate composition was modeled using the Monte-Carlo method. Mesoscopic numerical calculation of the uniaxial compressive strength and damage mechanism of a cubic, random aggregate sample of rubber concrete was performed based on a plastic damage model. The study of the damage mechanism in rubber concrete and the impacts of the rubber content and aggregate-mortar interfaces on the compressive strength of rubber concrete was conducted on a mesoscopic scale.

\section{Computation Analysis Model}

2.1. Random Rubber Particle Concrete Construct. For simplicity, the rubber particles in the model were assumed to be spheres. Based on the Walraven formula, the threedimensional distribution of rubber particles was converted to a two-dimensional distribution. The Walraven formula is based on the Fuller formula, which is used to convert threedimensional grading curves into the aggregate diameter of $d(\mathrm{~mm})<d_{0}(\mathrm{~mm})$, with a probability of $P_{c}\left(d<d_{0}\right)$ at any point along a cross section through the test sample [14]:

$$
\begin{aligned}
& P_{c}\left(d<d_{0}\right)=\varphi_{k}\left[1.065\left(\frac{d_{0}}{d_{\max }}\right)^{0.5}-0.053\left(\frac{d_{0}}{d_{\max }}\right)^{4}\right. \\
& \quad-0.012\left(\frac{d_{0}}{d_{\max }}\right)^{6}-0.045\left(\frac{d_{0}}{d_{\max }}\right)^{8} \\
& \left.\quad+0.0025\left(\frac{d_{0}}{d_{\max }}\right)^{10}\right] .
\end{aligned}
$$

In (1), $d_{\max }$ is the maximum aggregate particle diameter, and $\varphi_{k}$ is the ratio of the aggregate (including coarse rubber and fine aggregate) volume to the total volume. The number of corresponding aggregate particles, $n_{i}$, along the test sample cross section is

$$
n_{i}=\left(p_{c}^{i}-p_{c}^{j}\right) \frac{A}{A_{i}}
$$

where $A$ is the sample cross-sectional area and $A_{i}$ is the crosssectional area of a particular aggregate particle, expressed in units of $\mathrm{mm}^{2}$. After applying this function to a concrete mixture, as shown in Table 1, the number of aggregate particles in a cross section was calculated. These aggregates were randomly generated in the test sample cross section by means of the Monte-Carlo method.

The cubic test samples used in this study measured $150 \mathrm{~mm}$ on each side. Their cross-sectional area measured $22,500 \mathrm{~mm}^{2}$. The rubber density was $1020 \mathrm{~kg} / \mathrm{m}^{3}$, and the rubber particle diameter was $1-3 \mathrm{~mm}$. The coarse aggregate was first divided into five ranges: $5-10 \mathrm{~mm}, 10-15 \mathrm{~mm}, 15-$ $20 \mathrm{~mm}, 20-25 \mathrm{~mm}$, and $25-30 \mathrm{~mm}$. The average within each range was taken as the representative aggregate diameter, and the rubber-mortar particle diameter was assigned a value of $2 \mathrm{~mm}$. According to (2) and in combination with Table 1, the number of rubber particles in each cross section corresponding to various rubber contents was calculated; the results are shown in Table 2. After determining the numbers of aggregate particles of various diameters, the corresponding numbers of particles were inserted into the two-dimensional test sample cross section. Coordinates of the centers of the circles $(x, y)$ of these particles were randomly generated using the Monte-Carlo method. Circular aggregates without overlaps were ensured in the test sample, as required by (3). The random rubber particle model is shown in Figure 1. The rubber concrete was thus composed of a four-phase material consisting of aggregate, rubber, mortar, and aggregate-mortar interfaces:

$$
\begin{aligned}
\sqrt{\left(x_{i}-x_{j}\right)^{2}+\left(y_{i}-y_{j}\right)^{2}} \geq & \eta\left(r_{i}+r_{j}\right) \\
& (i, j=1,2,3, \ldots, n ; i \neq j) .
\end{aligned}
$$

In the equation, $\eta$ is the aggregate region of influence coefficient, which was assigned a value of 1.05 , and $r_{i}$ and $r_{j}$ are the radii of spherical rubber aggregates $i$ and $j$, respectively.

\subsection{Constitutive Relations of Phases of Rubber Concrete and} Damage Evolution Model. The rubber concrete elements are viewed as being consisting of rubber, aggregate, mortar, and aggregate-mortar interface elements. The thicknesses of the actual interfaces are very small, based on the literature [9, $15,16]$, and we assigned the interface elements a thickness of $1 \mathrm{~mm}$. Material properties such as strength and stiffness were assigned to the various elements shown in Figure 2.

The mesoscopic finite elements of the rubber concrete in this study were used to analyze deformation, damage, and failure processes in various material components on a mesoscopic scale; continuum mechanics, damage mechanics, 
TABLE 2: Number of rubber particles under different rubber content.

\begin{tabular}{|c|c|c|c|c|c|c|c|c|}
\hline \multirow{2}{*}{ Specimen } & \multirow{2}{*}{ Content of rubber $\left(\mathrm{kg} / \mathrm{m}^{3}\right)$} & \multirow{2}{*}{$\varphi_{k}$} & \multicolumn{5}{|c|}{ Diameter of particles $(\mathrm{mm})$} & \multirow{2}{*}{$\begin{array}{c}\text { Number of } \\
2 \mathrm{~mm} \text { rubber particles }\end{array}$} \\
\hline & & & 27.5 & 22.5 & 17.5 & 12.5 & 7.5 & \\
\hline NCR0 & 0 & 0.74 & 2 & 3 & 7 & 18 & 66 & - \\
\hline NCR10 & 27.7 & 0.74 & 2 & 3 & 7 & 18 & 66 & 68 \\
\hline NCR20 & 55.4 & 0.74 & 2 & 3 & 7 & 18 & 66 & 138 \\
\hline
\end{tabular}

Note: the meaning of the specimen designation (e.g., NCR10) is as follows. NRC is crumb rubber concrete, and the number 10 means that the rubber content is $10 \%$ (volume of sand-size fraction).
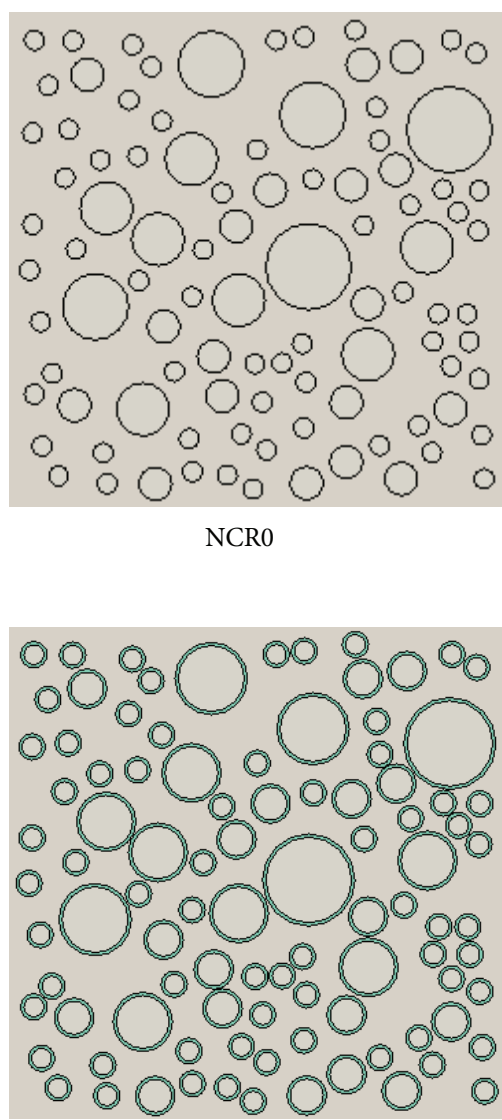

NCR0

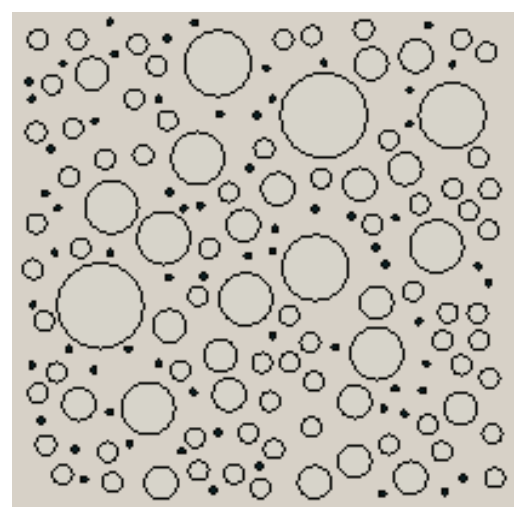

NCR10

(a) Without bonding interfaces

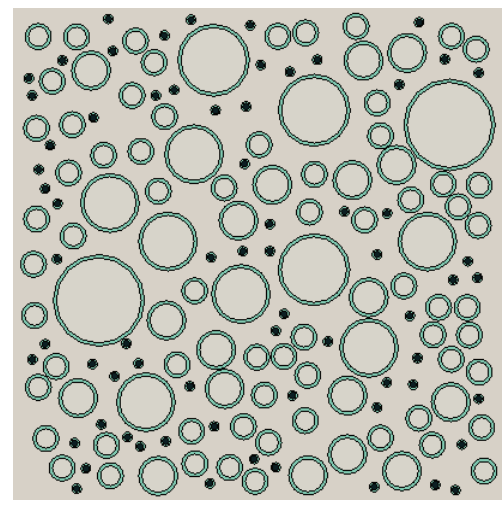

NCR10

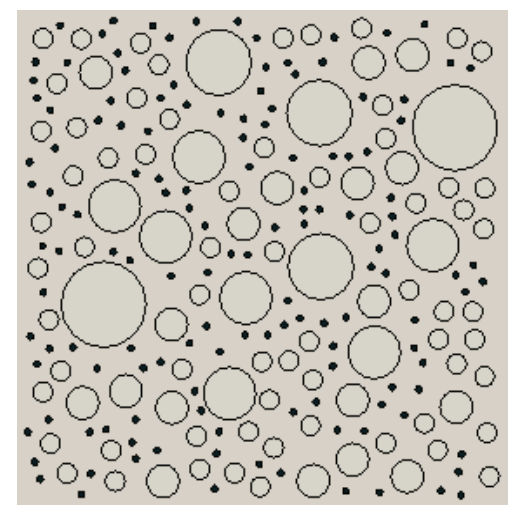

NCR20

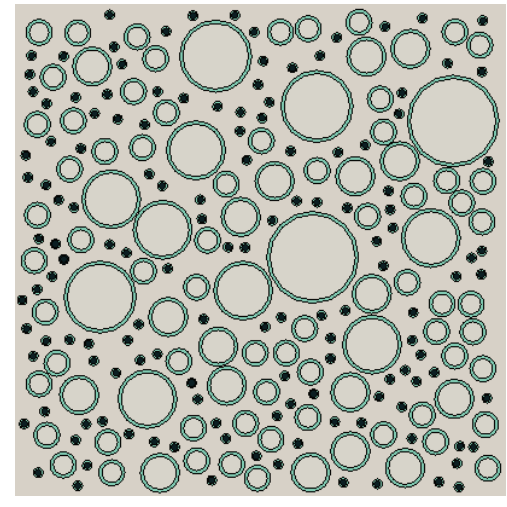

NCR20

(b) With bonding interfaces

FIGURE 1: Rubber concrete random-distribution model.
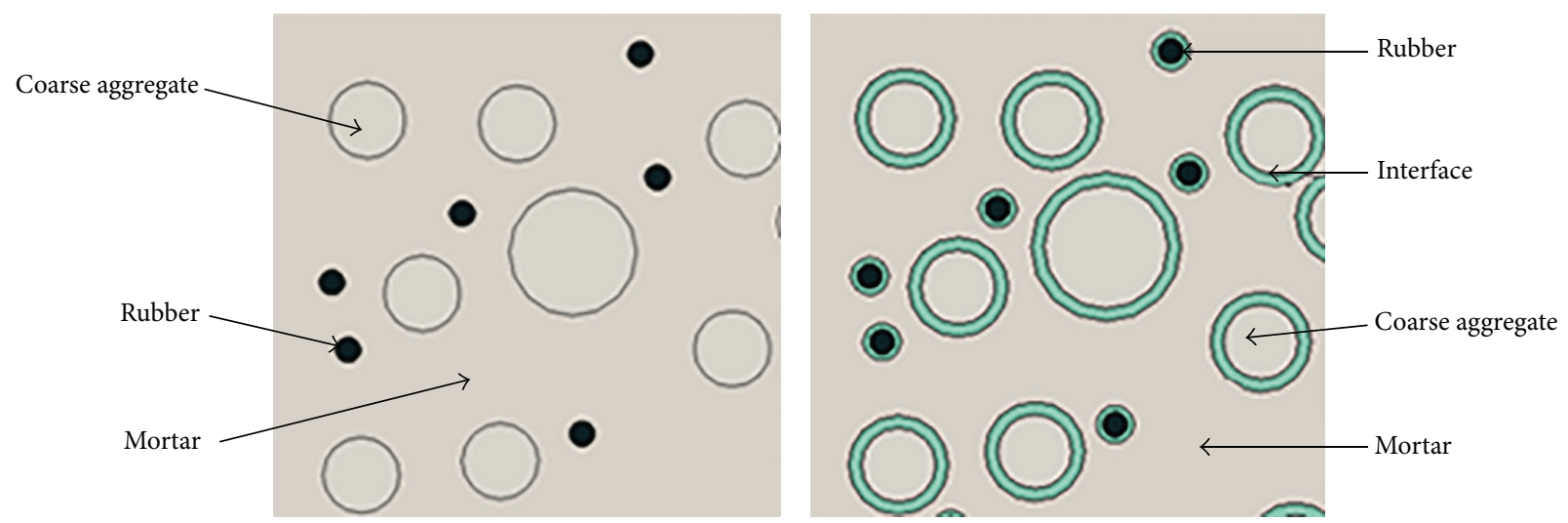

FIGURE 2: Element material property assignments. 
TABLE 3: Material properties [12].

\begin{tabular}{lcccc}
\hline Material & Elastic modulus $(\mathrm{MPa})$ & Poisson's ratio & Compressive strength $(\mathrm{MPa})$ & Tensional strength $(\mathrm{MPa})$ \\
\hline Mortar & 35,380 & 0.2 & 54.0 & 4.3 \\
Interface & 30,000 & 0.2 & 36.0 & 2.9 \\
Aggregate & 50,000 & 0.16 & 160 & 6.0 \\
Rubber aggregate & 80 & 0.499 & & \\
\hline
\end{tabular}

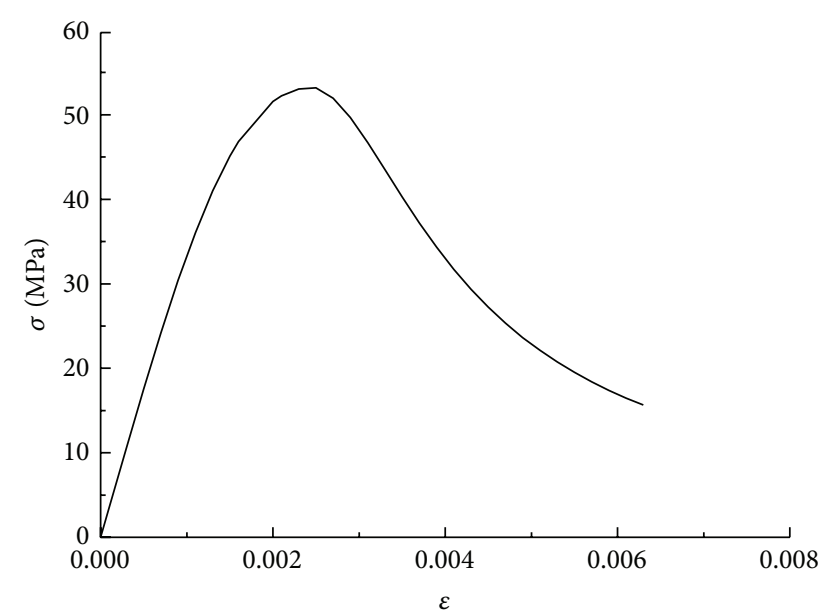

FIGURE 3: Mortar uniaxial compressive stress-strain constitutive curve.

and computational mechanics were used in combination. The degradation of the stiffness of various components is reflected by the tensile and compressive failure criteria and the damage model. The entire failure process of the rubber concrete test sample can be characterized using the finite-element method to simulate the compression failure mode.

(1) Mortar. Similar to concrete, mortar is also a type of quasibrittle material. Its stress-strain behavior displays nonlinear characteristics. In addition to plastic deformation, structural damage is primarily caused by the initiation and propagation of microfractures. Therefore, an elastic-plastic damage mechanical constitutive relation can be used to describe the mechanical properties of the concrete in the mesoscopic model. According to the Lemaitre strain equivalence principle, the constitutive relation of the damaged material can be expressed as the relationship between the normal stress $\sigma$ and normal strain $\varepsilon$ :

$$
\begin{aligned}
& E=(1-D) E_{0}, \\
& \sigma=E \varepsilon,
\end{aligned}
$$

$$
(0 \leq D \leq 1) \text {. }
$$

In this equation, $E_{0}$ is the initial elastic modulus, $E$ is the elastic modulus after damage, and $D$ is the damage variable.

The experimentally measured stress-strain curve is used as the mortar's compression constitutive relation in this paper, as shown in Figure 3. The mortar's uniaxial tension is in a linear elastic stage before the tensile stress reaches its peak value. The damage variable is determined using [17]

$$
D_{k}=\frac{(1-\beta) \varepsilon^{\mathrm{in}} E_{0}}{\alpha_{k}+(1-\beta) \varepsilon^{\mathrm{in}} E_{0}}, \quad(k=t, c) .
$$

In this equation, $t$ and $c$ represent tension and compression, respectively; $\beta$ is the ratio of plastic to nonplastic strain, which is 0.35-0.7 under compression and 0.5-0.95 under tension; and $\varepsilon^{\text {in }}$ is the nonelastic strain of the concrete under tensile or compressive conditions.

(2) Coarse Aggregate. Both compressive strength and elastic modulus of the coarse aggregate are relatively high; typically, the compressive strength of coarse aggregate is in the range of 150-200 MPa. Numerical computation reveals that the impact on the test sample's compressive strength is small when the compressive strength of the coarse aggregate is within this range. Based on the values for coarse aggregate in the relevant literature $[9-11,16]$, the mechanical parameter values that were used in this study are listed in Table 3.

(3) Rubber Particles. According to [12, 18], the elastic modulus of the rubber in rubber concrete is low, and the allowable deformation is high. The stress exerted on the rubber during damage to rubber concrete is small, and none of the rubber particles were damaged. Therefore, the rubber can be assumed to be an isotropic linear elastic material (see Table 3). It is assumed that the bonding of rubber particles to the concrete base is robust and will not separate during the computation process.

(4) Interface. In general, the coarse aggregate-mortar interface has the characteristics of relatively large porosity and relatively low density and strength. Therefore, the mechanical properties of the interface elements are associated with a certain degree of strength reduction. Due to the difficulty of measuring the interface layer mechanical properties, the researchers generally take $1 / 3$ to 1 times the mortar base strength as the strength of the interface. In this paper, the interface layer strength was taken to be $2 / 3$ to 1 times (i.e., interface layer not taken into account) the base strength. The purpose of using both of these values is to ascertain the impact of the interface layer's mechanical properties on the test sample's strength and to compare this with experimental data to develop values for the interface mechanical parameters (see Table 3 for parameter list). 


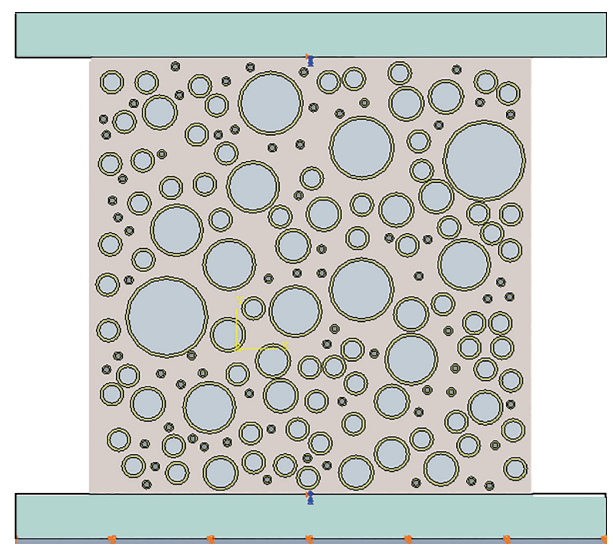

(a) Numerical computation model

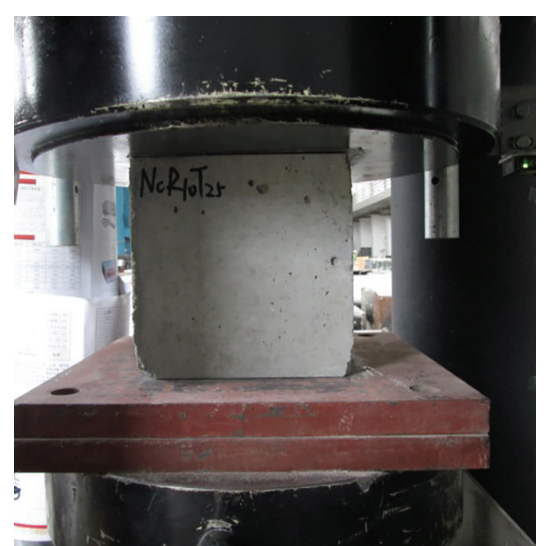

(b) Loading experiment apparatus

FIGURE 4: Uniaxial compression of concrete cubic standard test sample.

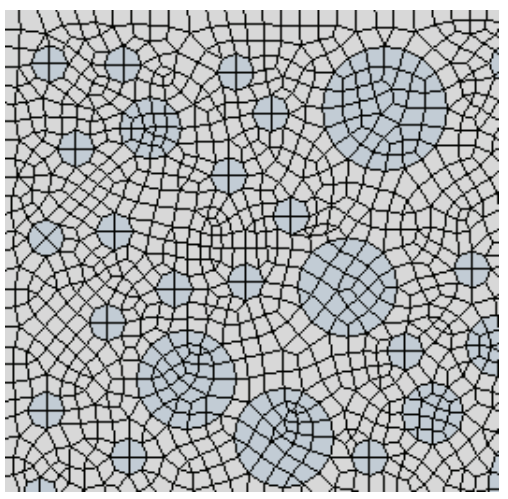

NCR0

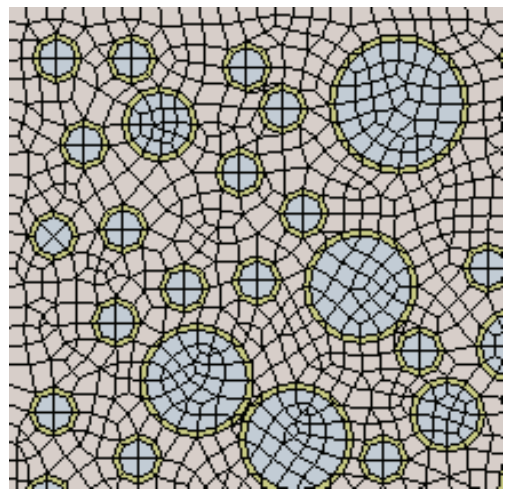

NCR0

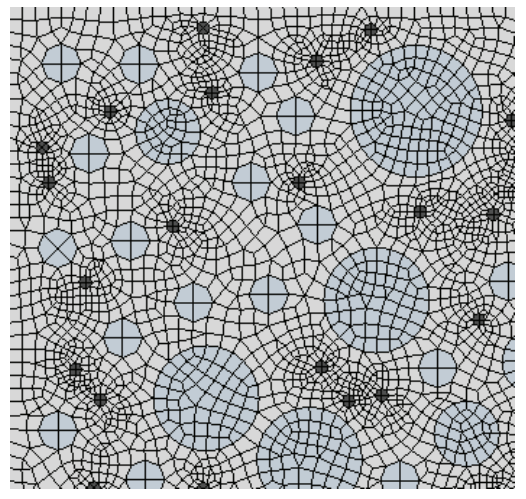

NCR10

(a) Bond interface not taken into account

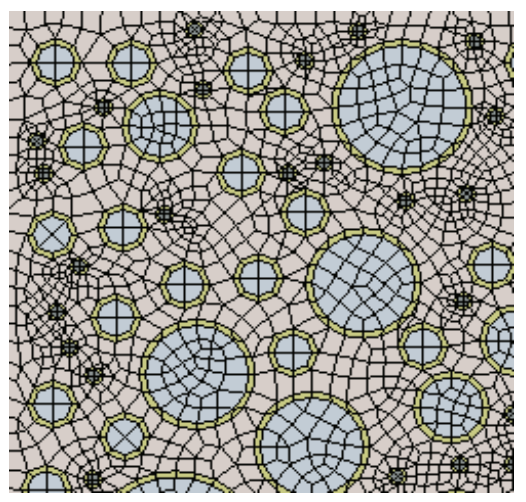

NCR10

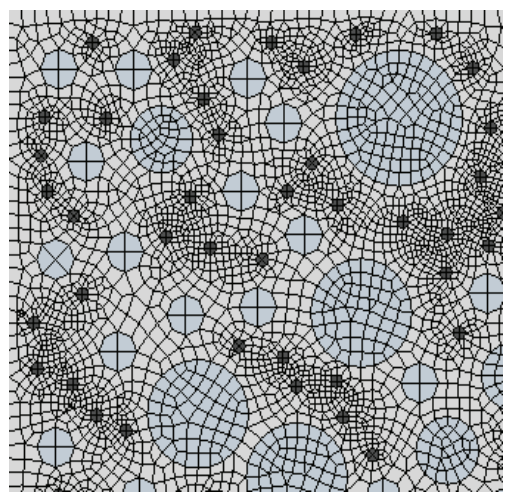

NCR20

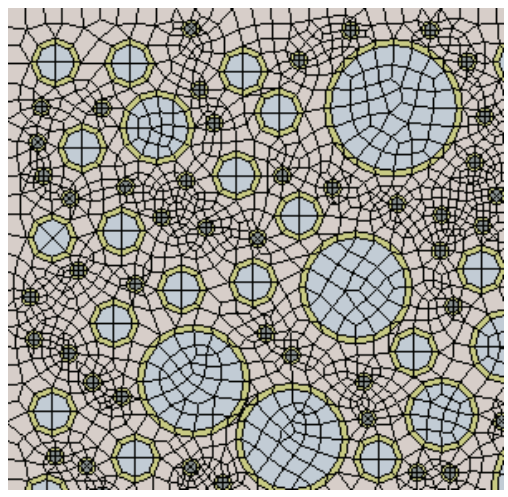

NCR20

(b) Bond interface taken into account

FiguRE 5: Enlarged finite-element meshes of various rubber contents.

\section{Computational Analysis of Cubic Rubber Concrete Standard Test Sample}

To evaluate the fracture initiation, propagation, and damage mechanism of the rubber concrete on a mesoscopic scale, the function of the rubber and interface layer in the concrete damage process and the effect of the rubber content and interface layer strength on the compressive strength were investigated. Three random aggregate rubber particle content distributions $(0 \%, 10 \%$, and $20 \%)$ were developed, both with and without consideration of the interface. While holding other parameters constant, the damage to the test sample under compression was simulated. 


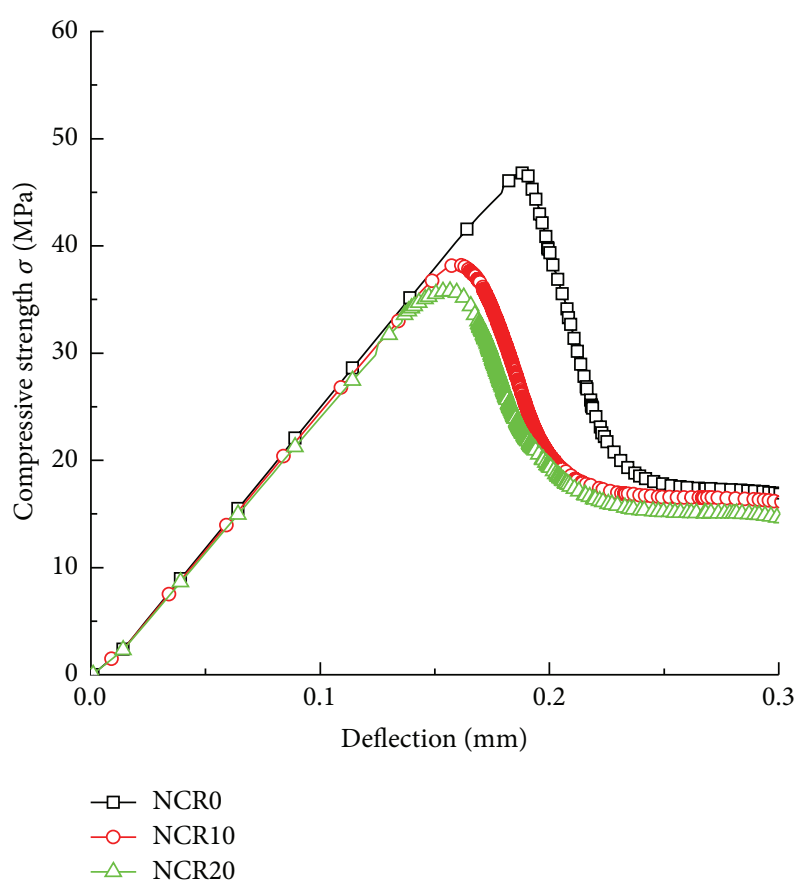

Figure 6: Load displacement $P-\delta$ curve for various rubber contents without taking into account the interface layer.

The computational analysis model was a plane stress model, and the test sample measured $150 \mathrm{~mm}$ on each side. Mesoscopic elements were used to simulate the four-phase material consisting of rubber, coarse aggregate, mortar, and interface elements and to then assign them corresponding material properties. The mesh element size was assigned a value of $2 \mathrm{~mm}$. According to $\mathrm{Ma}$ et al. [10], the computational results with this mesh size tend to be stable and fully reflect the nonuniformity of the mesoscopic character of the concrete. Figure 5 shows an enlarged view of the local finite-element mesh with various rubber contents. The boundary conditions include a hinged mount for the bottom plate, and horizontal constraints are exerted on the center of the upper and lower interfaces of the test sample to prevent horizontal movement. The steel plate is connected to the test sample in the form of interface contact, and the friction coefficient between the two is assumed to be 0.5 . Displacement-controlled loading is exerted on the center of the top steel plate. The numerical computation model is shown in Figure 4(a).

Figure 6 shows the uniaxial compressive load displacement curve for different rubber contents without taking into account the aggregate-mortar interfaces (i.e., the interface strength is equal to the base strength). The plots show that as the rubber content increases the compressive strength of the concrete and its peak strain value decrease, although the degree of strength reduction decreases in a nonlinear fashion. The elastic modulus displays a slight decreasing trend. After the peak load is applied, the slope of the strength reduction decreases with increasing rubber content. These results indicate that the rubber concrete exhibited strong ductility after the peak loading.

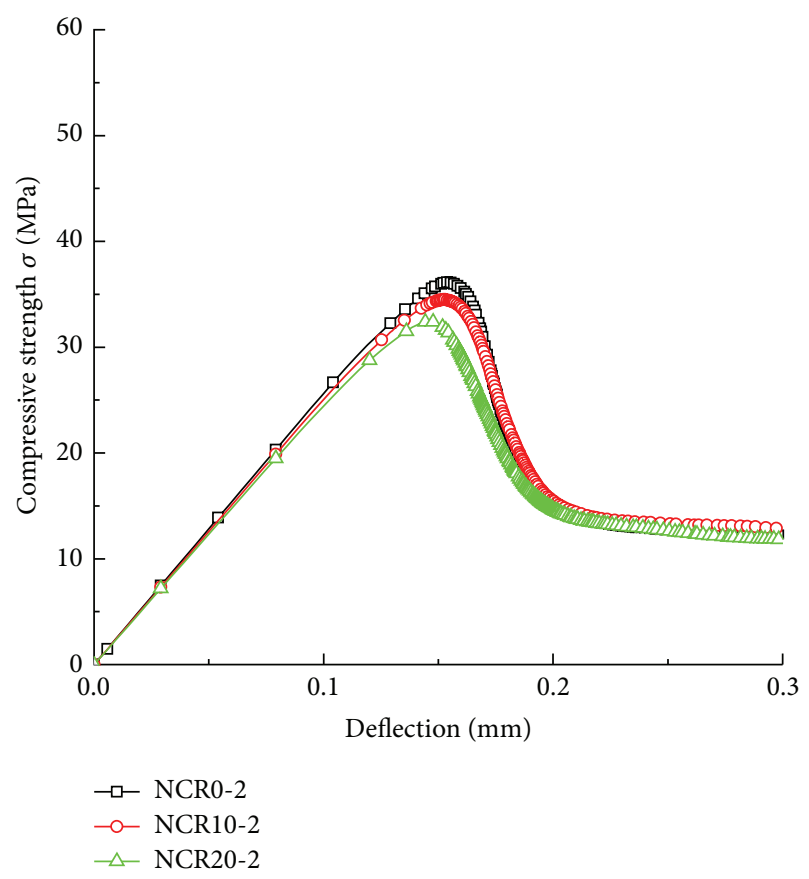

Figure 7: Load displacement $P-\delta$ curve for various rubber contents taking into account the interface layer.

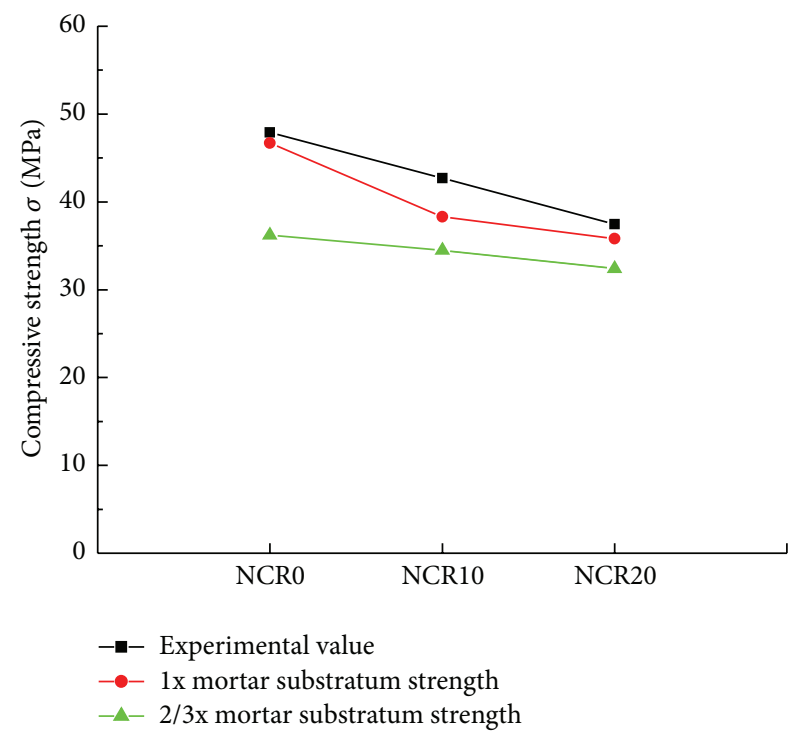

FIgURE 8: Comparison of various computational and experimental values.

Figure 7 shows the concrete uniaxial compressive load displacement curve for various rubber contents while taking into account the aggregate-mortar interfaces (i.e., interface strength is $2 / 3$ of the base strength). The results indicate that as the rubber content increases the compressive strength, peak strain, and elastic modulus all decrease roughly proportionally. After the peak loading, the slope of the reduction decreases with increasing rubber content.

Figure 8 shows the compressive strengths of the mesoscopic modeling and experimental measurement. The three 


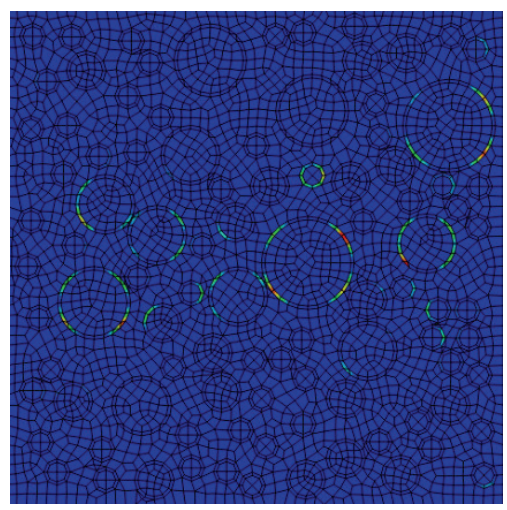

$0.1 \mathrm{~mm}$

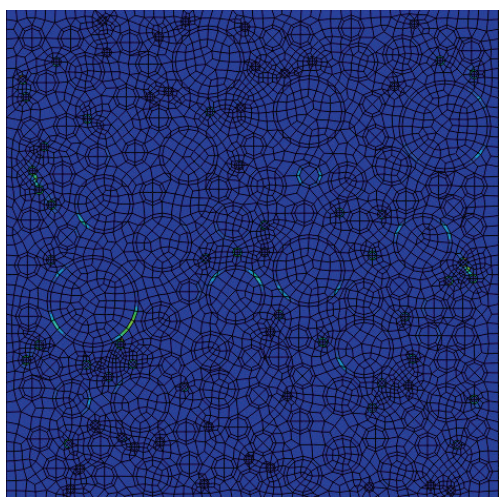

$0.1 \mathrm{~mm}$

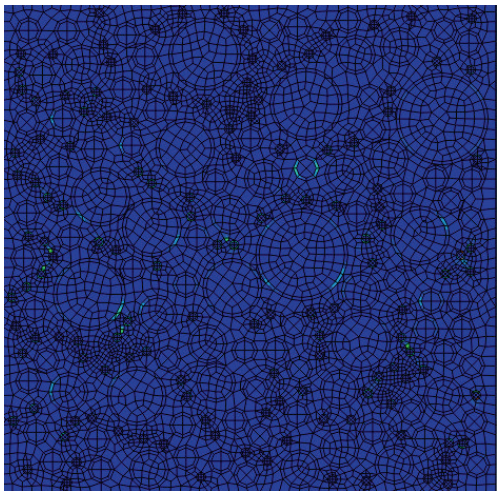

$0.1 \mathrm{~mm}$

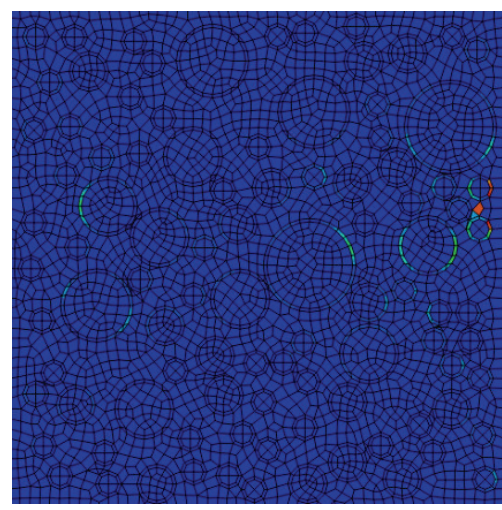

$0.15 \mathrm{~mm}$

(a) NCR0

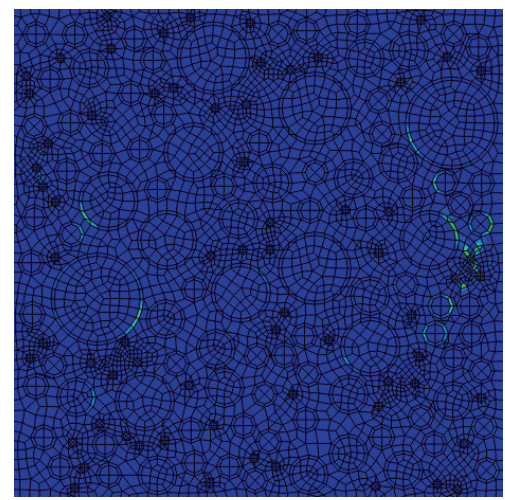

$0.15 \mathrm{~mm}$

(b) NCR10

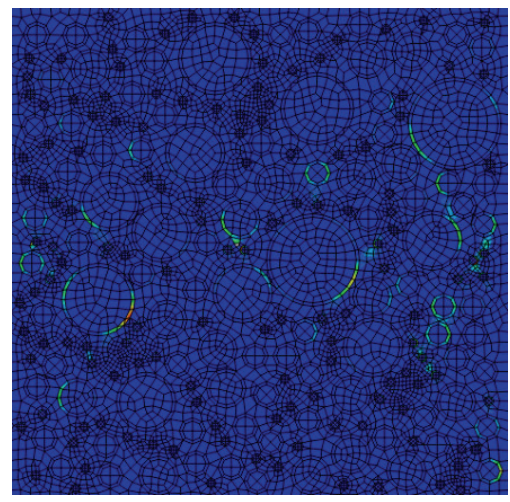

$0.15 \mathrm{~mm}$

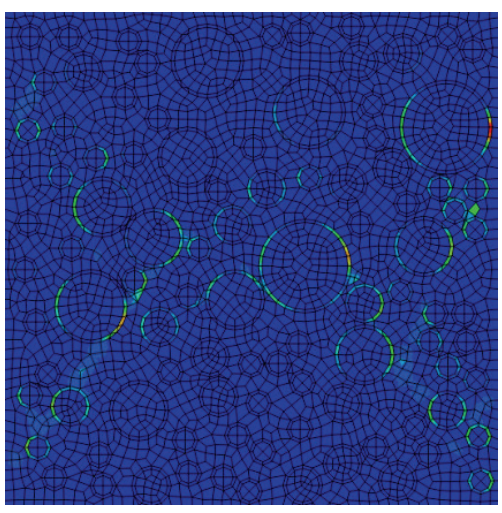

$0.2 \mathrm{~mm}$

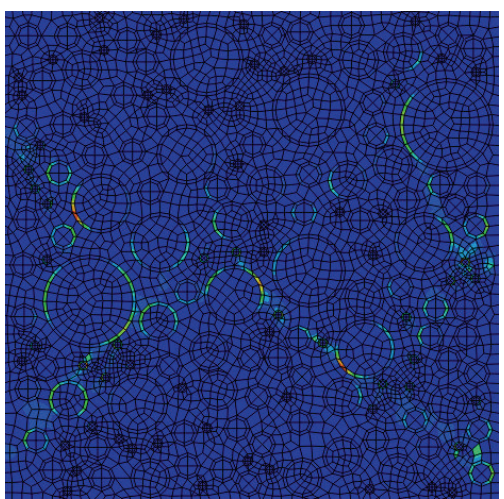

$0.2 \mathrm{~mm}$

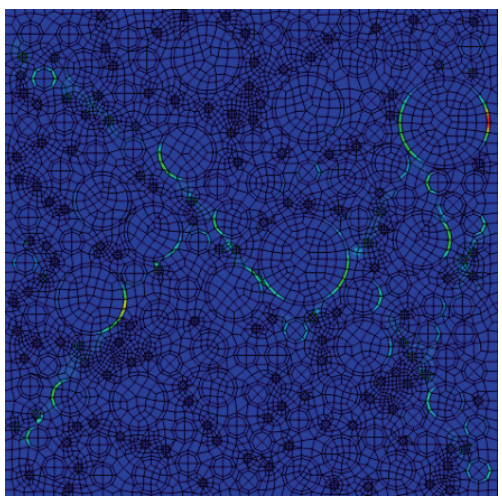

$0.2 \mathrm{~mm}$

(c) NCR20

FIgURE 9: Fracture distribution in rubber concrete, taking into account the bonding interfaces.

curves in the figure are the experimental and computational results when the interface strength is set to $1 \mathrm{x}$ and $2 / 3 \mathrm{x}$ the substratum strength, respectively. As the rubber content increases from 0 to $20 \%$, the experimental values of the compressive strength decrease roughly proportionally. With every $10 \%$ increase in the rubber content, the compressive strength decreases approximately $5 \mathrm{MPa}$. In the mesoscopic computation, when the interface strength is $2 / 3$ of the substratum strength, the rubber concrete's compressive strength also decreases roughly proportionally. The degree of reduction, however, is less than that of the experimental values: every $10 \%$ increase in the rubber content produces a decrease in the compressive strength of approximately $2 \mathrm{MPa}$. At a constant rubber content, the difference between the computed and experimental values is $10-23 \%$. When the interface strength is assumed to be equal to the substratum strength (i.e., interface not taken into account), the rubber concrete's compressive strength is reduced, but to a lesser degree. When the rubber content is $0 \%$ and $20 \%$, the computed compressive strength is very close to the actual 


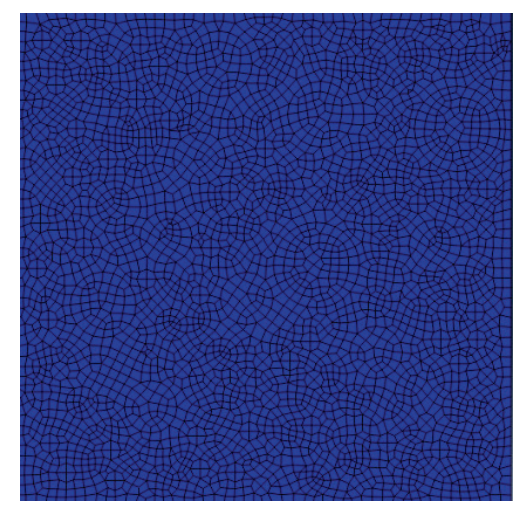

$0.1 \mathrm{~mm}$

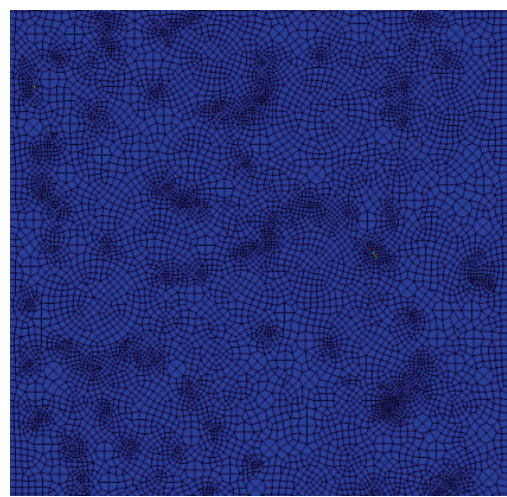

$0.1 \mathrm{~mm}$

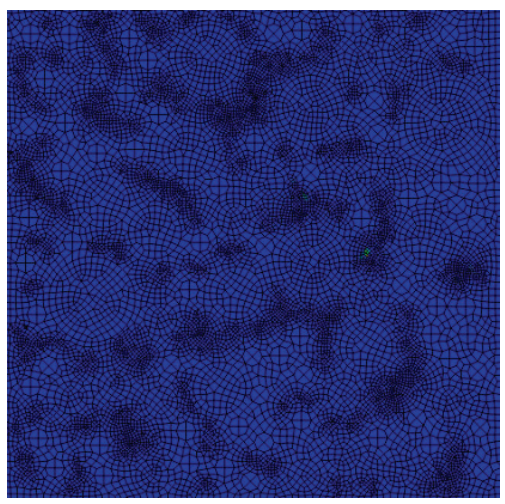

$0.1 \mathrm{~mm}$

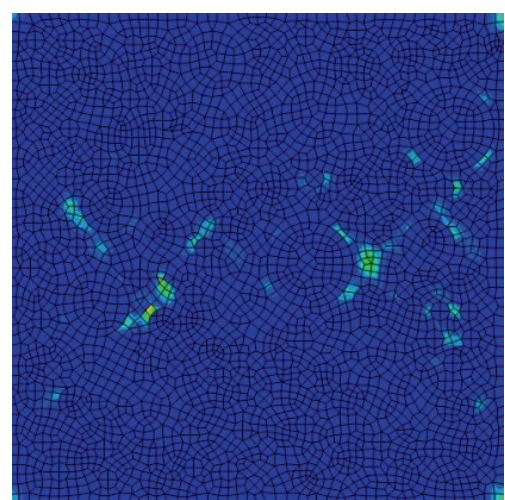

$0.15 \mathrm{~mm}$

(a) NCR0

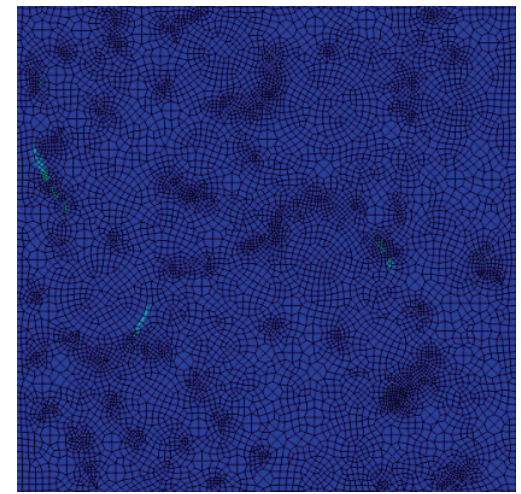

$0.15 \mathrm{~mm}$

(b) NCR10

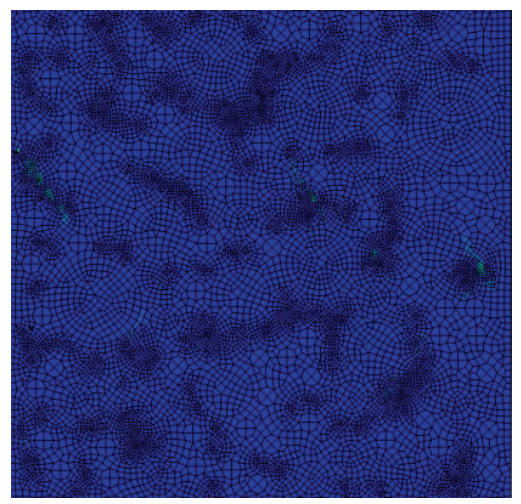

$0.15 \mathrm{~mm}$

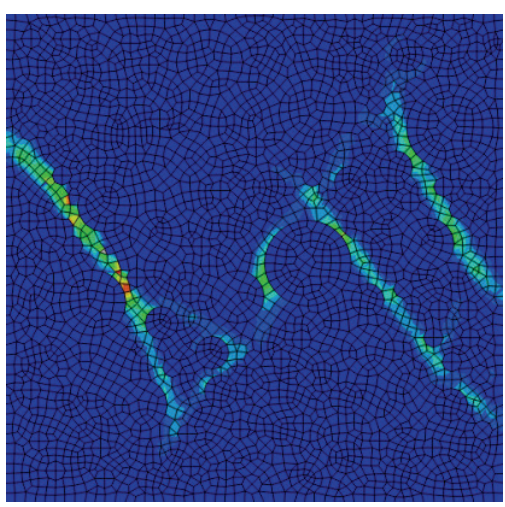

$0.2 \mathrm{~mm}$

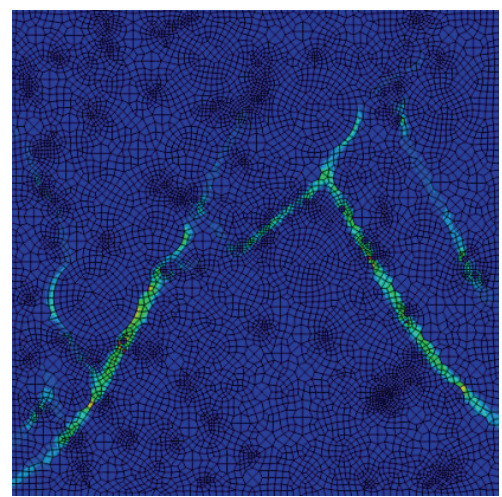

$0.2 \mathrm{~mm}$

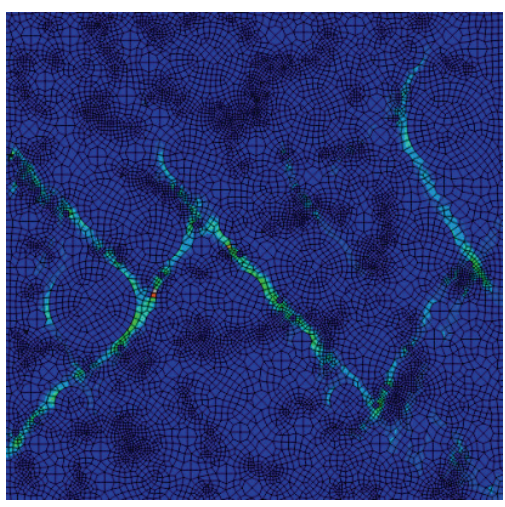

$0.2 \mathrm{~mm}$

(c) NCR20

FIgURE 10: Fracture distribution in rubber concrete without taking into account the bonding interfaces.

experimentally measured value, with approximately a $3 \%$ difference.

\section{Entire Uniaxial Compression and Damage Process of Rubber Concrete Cubical Test Sample}

Figure 9 shows the fracture propagation in the rubber concrete under uniaxial compression while taking into account the bonding interface. The loading displacement reached $0.1 \mathrm{~mm}, 0.15 \mathrm{~mm}$, and $0.2 \mathrm{~mm}$. Fractures first appeared along the relatively weak interfaces; these were dispersed and discontinuous. As the pressure increased, only a few fractures connected by extending around the coarse aggregate. At a constant displacement, as the rubber content increases, the number of fractures along the interfaces and the total number of fractures decreased slightly. The eventual connected fractures were concentrated primarily near rubber particles. 

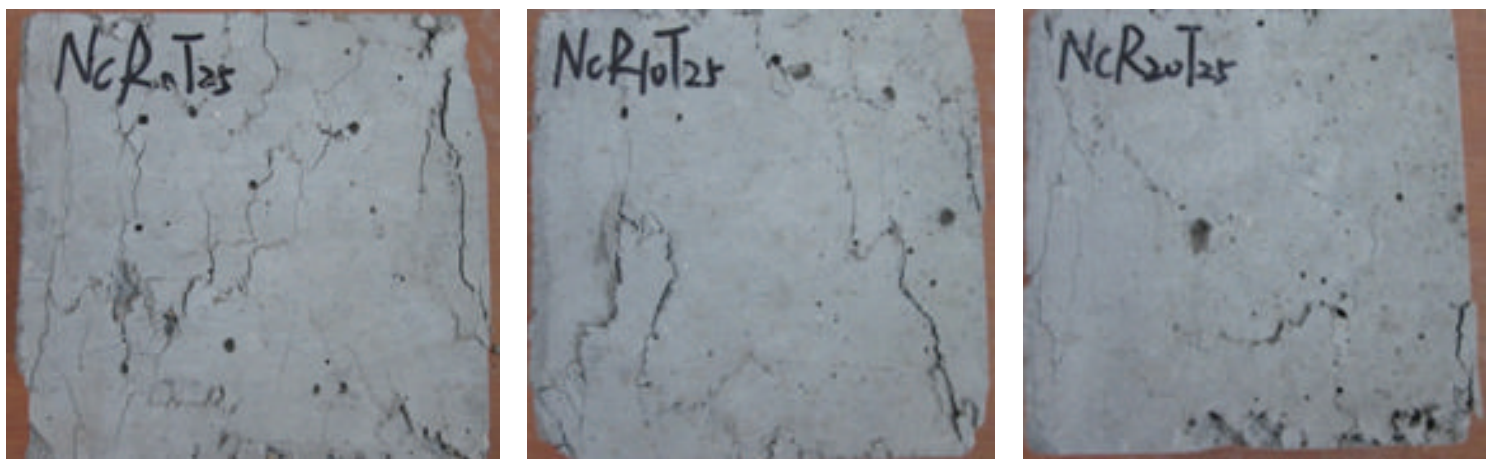

FIGURE 11: Actual measured fracture distribution in rubber concrete.

Therefore, the inclusion of rubber particles increased the ductility of the concrete and improved the concrete's deformation performance.

Figure 10 shows the fracture propagation in rubber concrete without taking into account the bonding interface. When the displacement was $0.15 \mathrm{~mm}$, many fractures appeared in the concrete without rubber. As the load increased, fractures extended around the coarse aggregate and became connected. As rubber content increased the number of fractures increased slightly, while the width of the fractures decreased slightly; that is, the fractures became narrower and denser. The fractures extended around the coarse aggregate and connected and also propagated towards the rubber particles.

A comparison of Figures 9 and 10 indicates that there is a relatively large difference in the concrete damage mechanism depending on whether the bonding interface is taken into account. When a weak bonding interface is assumed, the fractures first appear along the interfaces, and only a few fractures are connected at the time of eventual failure. In other words, the fractures near the interfaces tend to be discontinuous due to the relatively strong mortar substratum between the fractures. The weaker the interface is, the more evident this phenomenon becomes. When the bonding interface is not taken into account, the fractures propagate and connect; fewer, wider fractures develop; and the brittleness is evident.

Figure 11 shows the actual fracture propagation distribution. As the rubber content increases, the fractures in the test sample surface are few and are connected, which is similar to the fracture distribution in rubber concrete without taking into account the bonding interface.

\section{Conclusions}

The damage to a cubic rubber concrete sample under load was numerically simulated on a mesoscopic scale, based on a plastic damage model. The following conclusions were developed.

(1) A direct view of the entire process of microfracture initiation, propagation, and connection can be achieved using mesoscopic numerical computation on rubber concrete with a random aggregate model. Under uniaxial loading, the damage to the random aggregate model is similar to that obtained experimentally.

(2) As the rubber content increases from 0 to $20 \%$, the compressive strength of rubber concrete decreases. At a constant rubber content, the calculated compressive strength is very close to the experimentally measured value, within an error of $3 \%$, when the interface strength is set equal to the substratum strength (i.e., the interface is not taken into account). This error increased and reached $10-23 \%$ when the interface strength was assigned a value of $2 / 3$ of the substratum strength. Therefore, the computational results reductions in the interface strength are not taken into account being closer to the experimental results.

(3) Fractures in rubber concrete first appear along the interfaces between the aggregate and rubber-mortar elements. When the interface strength reduction is taken into account, the fractures along the interfaces tend to be discontinuous due to the relatively highstrength mortar in between; the deformation of the test sample is concentrated primarily in the interface layer. When the interface strength is not taken into account, fractures produced along the interfaces tend to propagate and connect as the load is applied, and the eventual damage mode is consistent with the experimental observations.

\section{Conflict of Interests}

The authors declare that there is no conflict of interests regarding the publication of this paper.

\section{Acknowledgments}

The authors gratefully acknowledge the financial support provided by the National Natural Science Foundation (Project nos. 51278132, 11372076), Science and Technology Planning Project of Guangdong Province (2014A020216053), Science and Technology Planning Project of Guangzhou City (201510010096, 201510010042), Technology Planning Project of Huangpu District (201356), and Foundation of Guangdong Provincial Department of Transport (Project nos. 2013-02017, 2013-04-006). 


\section{References}

[1] P. Sukontasukkul, "Use of crumb rubber to improve thermal and sound properties of pre-cast concrete panel," Construction and Building Materials, vol. 23, no. 2, pp. 1084-1092, 2009.

[2] I. B. Topçu and N. Avcular, "Collision behaviours of rubberized concrete," Cement and Concrete Research, vol. 27, no. 12, pp. 1893-1898, 1997.

[3] F. Hernández-Olivares and G. Barluenga, "Fire performance of recycled rubber-filled high-strength concrete," Cement and Concrete Research, vol. 34, no. 1, pp. 109-117, 2004.

[4] H. A. Toutanji, "The use of rubber tire particles in concrete to replace mineral aggregates," Cement and Concrete Composites, vol. 18, no. 2, pp. 135-139, 1996.

[5] H. Huynh and D. Raghavan, "Durability of simulated shredded rubber tire in highly alkaline environments," Advanced Cement Based Materials, vol. 6, no. 3-4, pp. 138-143, 1997.

[6] F. Liu, G. Chen, L. Li, and Y. Guo, "Study of impact performance of rubber reinforced concrete," Construction and Building Materials, vol. 36, pp. 604-616, 2012.

[7] I. B. Topçu, "The properties of rubberized concretes," Cement and Concrete Research, vol. 25, no. 2, pp. 304-310, 1995.

[8] Y. C. Guo, J. H. Zhang, G. Chen, G. M. Chen, and Z. H. Xie, "Fracture behaviors of a new steel fiber reinforced recycled aggregate concrete with crumb rubber," Construction and Building Materials, vol. 53, pp. 32-39, 2014.

[9] A. K. H. Kwan, Z. M. Wang, and H. C. Chan, "Mesoscopic study of concrete II: nonlinear finite element analysis," Computers and Structures, vol. 70, no. 5, pp. 545-556, 1999.

[10] H. F. Ma, H. Q. Chen, and B. K. Li, "Meso-structure numerical simulation of concrete specimens," Journal of Hydraulic Engineering, no. 2, pp. 27-35, 2004.

[11] X.-L. Du, L. Jin, and J.-Q. Huang, "Simulation of meso-fracture process of concrete using the extended finite element method," Chinese Journal of Computational Mechanics, vol. 29, no. 6, pp. 940-947, 2012.

[12] F. Liu, D.-P. Pan, L.-J. Li, and Y.-Q. Chen, "Numerical simulation on micro-level of stress and strength in crumb rubber concrete," Journal of Building Materials, vol. 11, no. 2, pp. 144-151, 2008.

[13] H. Wang, C. Zhang, L. Yang, and Z. You, "Study on the rubber-modified asphalt mixtures' cracking propagation using the extended finite element method," Construction and Building Materials, vol. 47, pp. 223-230, 2013.

[14] J. C. Walraven and H. W. Reinhardt, “Theory and experiments on the mechanical behavior of cracks in plain and reinforced concrete subjected to shear loading," HERON. A, vol. 26, no. 1, pp. 26-35, 1991.

[15] Z. P. Bažant and B. H. Oh, "Crack band theory for fracture of concrete," Matériaux et Constructions, vol. 16, no. 3, pp. 155-177, 1983.

[16] G. Liu and Z. Wang, "Numerical simulation study of fracture of concrete materials using random aggregate model," Journal of Tsinghua University, vol. 36, no. 1, pp. 84-89, 1996.

[17] J. Zhang, Q. Wang, S. Hu, and C. Wang, "Parameters verification of concrete damaged plastic model of ABAQUS concrete damage plastic model parameter verification," Building Structure, no. 8, pp. 127-130, 2008.

[18] H. Huynh, D. Raghavan, and C. F. Ferraris, "Rubber particles from recycled tires in cementitious of composite materials," National Institute of Standards and Technology Interagency Report (NISTIR) 5850R, 1996. 

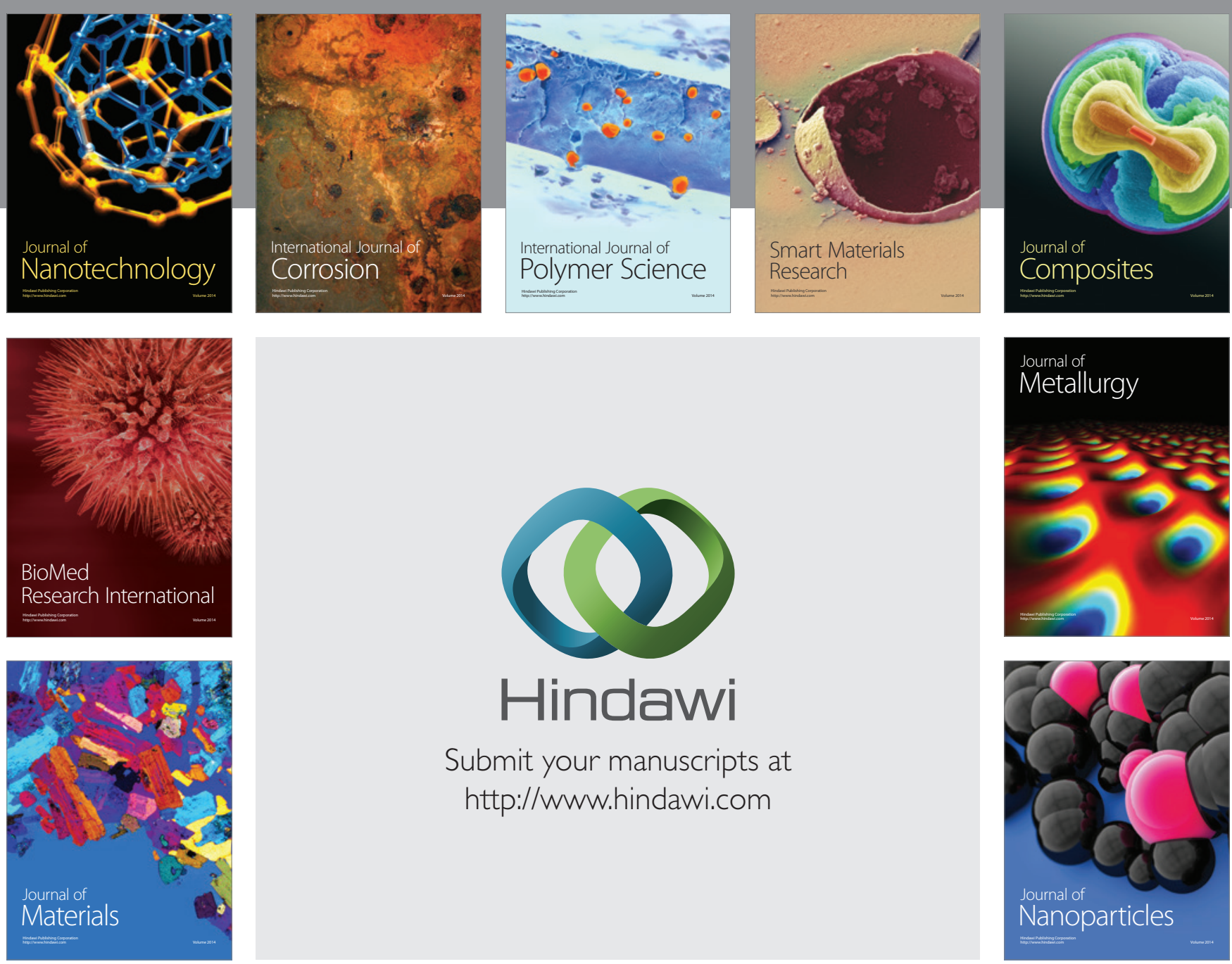

Submit your manuscripts at http://www.hindawi.com
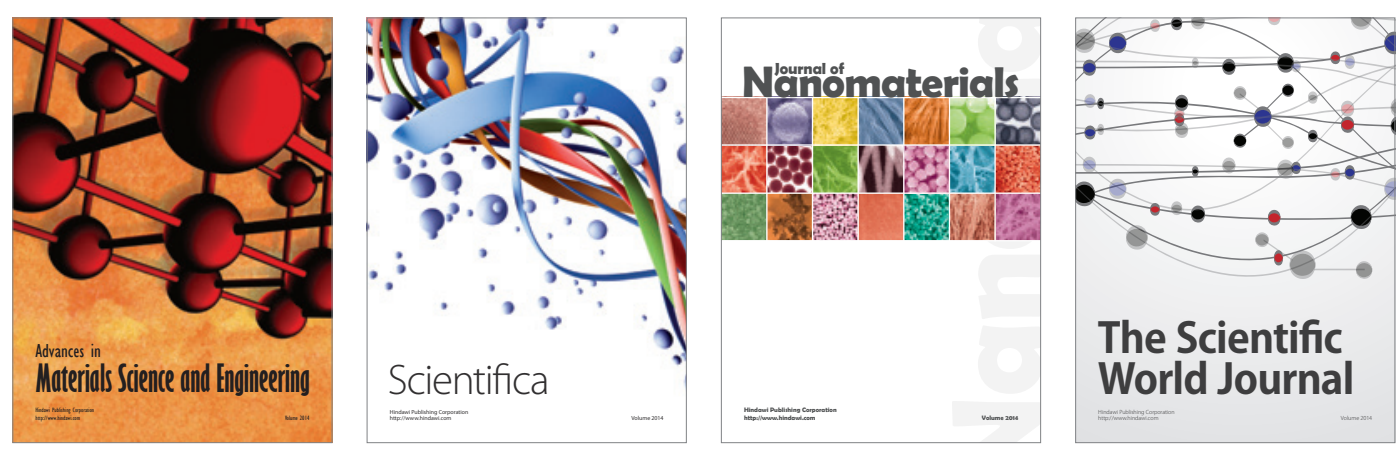

\section{The Scientific World Journal}
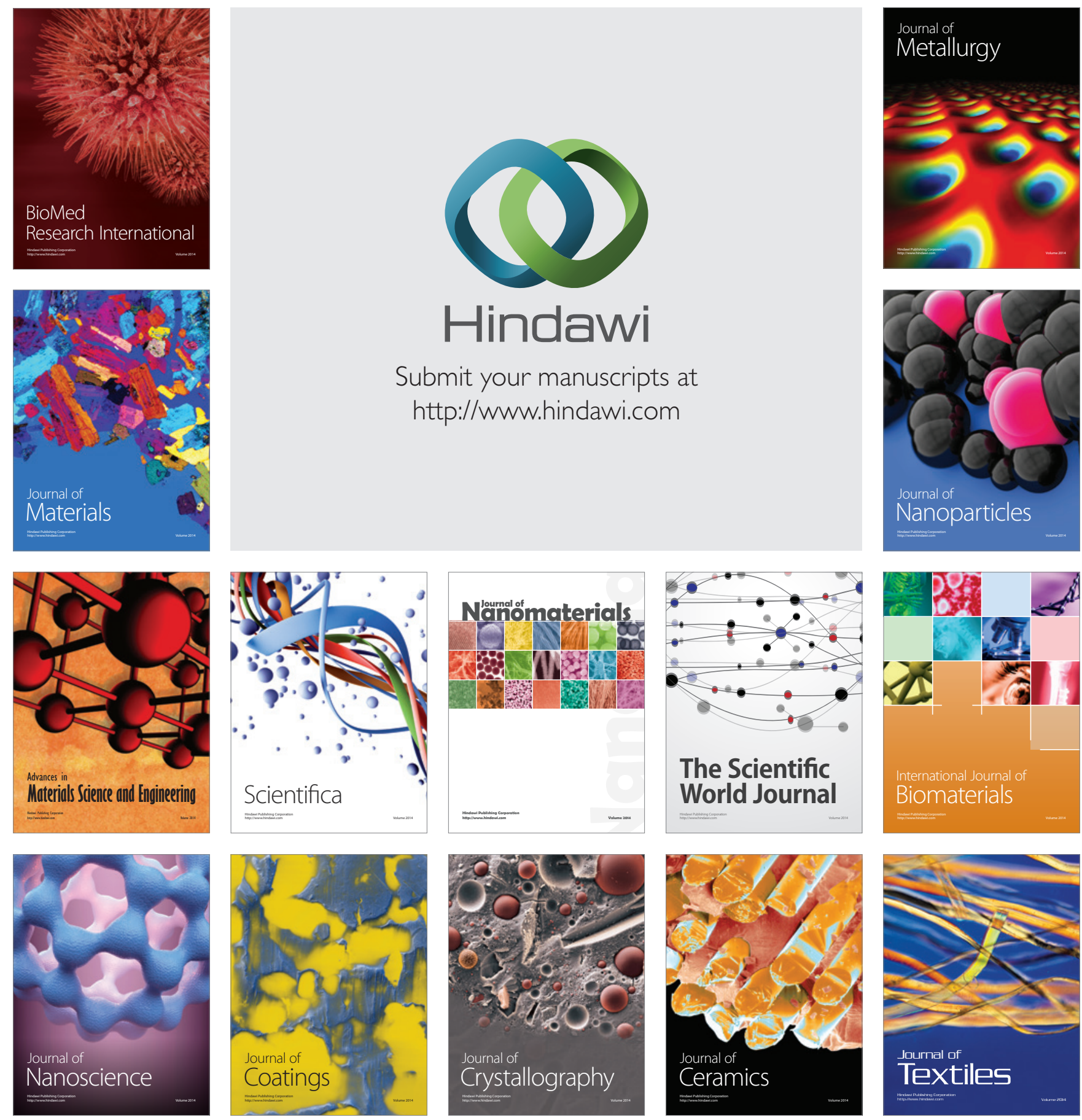